\title{
Substantial reduction of critical current for magnetization switching in an exchange-biased spin valve
}

Y. JIANG, T. NOZAKI, S. ABE, T. OCHIAI, A. HIROHATA, N. TEZUKA AND K. INOMATA

Nature Materials 3, 361-364 (2004).

It has been drawn to the journal's attention that there is considerable overlap between an earlier publication by these authors ${ }^{1}$ and the material presented in this paper. At no time during the consideration of this paper for publication in Nature Materials did the authors inform our editorial staff of the consideration of this related work by another journal. The authors' failure to do so constitutes a clear breach of the strict publication policy of Nature Materials (http://www.nature.com/nmat/authors/auguide.html).

Our readers are reminded that our editorial policy requires that all submissions to Nature Materials must be accompanied by copies of all related papers that are currently under cons ideration elsewhere. This includes work submitted elsewhere after the original date of submission to Nature Materials. For further discussion of these issues, readers are directed to the editorial of the January 2005 issue of Nature Materials.

1. Jiang, Y. et al. Effective reduction of critical current for current-induced magnetization switching by a Ru layer insertion in an exchange-biased spin valve. Phys. Rev. Lett. 92, 167204 (2004).

2. The cost of salami slicing. Nature Mater. 4, 1 (2005).

\section{ATP-independent contractile proteins from plants}

MICHAEL KNOBLAUCH, GUNDULA A. NOLL, TORSTEN MÜLLER, DIRK PRÜFER, INGRID SCHNEIDER-HÜTHER, DÖRTE SCHARNER, AART J. E. VAN BEL, WINFRIED S. PETERS

Nature Materials 2, 600-604 (2003)

In the above paper, we reported that the threshold concentration of free $\mathrm{Ca}^{2+}$ required to induce longitudinal contraction in forisomes was in the nanomolar range. Due to errors in estimating $\mathrm{Ca}^{2+}$ concentrations in $\mathrm{Ca}^{2+}$-buffered media, these calculated figures were incorrect. Recent tests in our lab have shown that the threshold concentration varies between 60 and $90 \mu \mathrm{M}$ under the conditions originally described. We wish to stress that this clarification does not bear on our conclusions regarding the biological function of forisomes and the technological potential of forisome-like proteinaceous smart materials. For a technical discussion of errors of the type we made, the reader is referred to C. Patton et al. (Cell Calcium 35, 427-431; 2004). 